\title{
DIAGNÓSTICO E DIRETRIZES PARA A REARBORIZAÇÃO DO CANTEIRO CENTRAL DA AVENIDA CARDEAL, JARDIM DAS GAIVOTAS, CARAGUATATUBA- SP.
}

\author{
Larissa Maximiliano do Prado'
}

Karolina Marie Alix Benedictte Van Sebroeck Dória²

Resumo: $A$ arborização está relacionada com a qualidade de vida, trazendo para o ambiente urbano benefícios como: a redução da poluição, abrigo e alimentação para a fauna, funções estéticas, paisagísticas e culturais. O presente estudo teve como objetivo realizar o levantamento cadastral das espécies arbóreas presentes na Av. Cardeal, no bairro Jardim das Gaivotas, no município de Caraguatatuba-SP e propor diretrizes para sua rearborização. Foram realizados a revisão bibliográfica e o levantamento arbóreo in loco. Foram catalogadas 562 árvores, das quais 43 estavam mortas, 68 não foram identificadas e 451 pertencem a 39 famílias botânicas. Dos indivíduos analisados, 23 apresentam estado fitossanitário ruim (acometidas por cupins), 43 estão mortas e 496 sadias. Notou-se que 54,1\% das espécies plantadas nesta área são exóticas, $44,8 \%$ são nativas e $1,1 \%$ são híbridos. Nas diretrizes a serem adotadas para uma proposta de rearborização urbana estão presentes espécies nativas, ornamentais, recomendadas para a arborização urbana, com potencial paisagístico e frutíferas para alimentação da avifauna que ocorre no seu entorno.

Palavras-chave: Arborização Urbana; Paisagem; Inventário da Arborização.

\footnotetext{
${ }^{1}$ Ciências Biológicas/Centro Universitário Módulo, Brasil. E-mail: laaari.maximiliano@gmail.com.

2 Ciências Biológicas/Centro Universitário Módulo, Brasil. E-mail: karolina.doria@modulo.edu.br.
} 